\title{
PENGARUH PELAKSANAAN PEMERIKSAAN PAYUDARA SENDIRI \\ (SADARI) TERHADAP PENGETAHUAN DAN KEMAMPUAN SISWI \\ DALAM UPAYA DETEKSI DINI KANKER PAYUDARA SMA SWAKARYA TAHUN 2017
}

\section{The Effect of Implementation of Own Breast Examination on Knowledge and Skills Ability in The Early Detection of Breast Cancer Breast Cancer Detection in 2017}

\author{
Martha Hutapea ${ }^{1}$ \\ ${ }^{1}$ Dosen Prodi D-III Kebidanan, Akademi Kebidanan Kharisma Husada \\ E-mail : marthahutapea38@gmail.com
}

\begin{abstract}
Abstrak
Kanker payudara merupakan kanker nomor dua terbanyak menyerang wanita diindonesia dan menjadi pembunuh nomor satu didunia. Salah satu cara mendeteksi dini kanker payudara yaitu dengan cara SADARI. Kebanyakan wanita tidak melakukan pemeriksaan SADARI karena kurangnya pengetahuan sehingga wanita yang melakukan SADARI masih rendah. Tujuan dari penelitian ini adalah untuk mengetahui pengaruh pendidikan kesehatan tentang pemeriksaan SADARI sebagai deteksi dini kanker payudara terhadap pengetahuan dan sikap remaja putri di SMK N 1 Karanganyar. Jenis penelitian ini adalah penelitian kuantitatif dengan rancangan penelitian preeksperimental dengan pretest-posttest design. Penelitian ini menggunakan teknik Cluster Sampling dengan jumlah responden sebanyak 31 responden. Analisa data dalam penelitian ini menggunakan uji Wilcoxon dan uji McNemar. Hasil analisa data tingkat pengetahuan diperoleh nilai $\mathrm{P}$ Value $=0.000$ dan analisa data sikap diperoleh nilai $\mathrm{P}$ Value $=$ 0.000. Hasil penelitian ini adalah ada pengaruh pendidikan kesehatan tentang pemeriksaan SADARI sebagai deteksi dini kanker payudara terhadap pengetahuan dan sikap remaja putri di SMK N 1 Karanganyar. Saran bagi peneliti selanjutnya dapat dilakukan dengan cara membandingkan pendidikan kesehatan menggunakan metode ceramah dan demonstrasi dengan metode ceramah dan metode video dan dilakukan dengan dua kelompok yaitu kelompok kontrol dan kelompok perlakuan.
\end{abstract}

Kata kunci: Pendidikan Kesehatan, Pengetahuan, Sikap dan Periksa Payudara Sendiri

\begin{abstract}
Breast cancer is the second largest that attacks women in Indonesia and the number one killer in the world. One of the early detection methods of breast cancer is breast selfexamination. Most women do not do self-examination due to their lack of knowledge of breast self-examination. The objective of this research is to investigate effect of the health education of breast self-examination as an early detection for cancer on the knowledge and attitude of female students of State Vocational High School 1 of Karanganyar. This research used the quantitative pre-experimental research method with the pretestposttest design. The samples of the research were taken by using the cluster sampling technique. They consisted of 31 respondents. The data of the research were analyzed by using Wilcoxon's test and McNemar's Test. The result of the test shows that the value of $p$ for the variable of Knoweldge is 0.000 and that of $\mathrm{p}$ for the variable of attitude is 0.000 , meaning that there is an effect of the health education of breast self-examination as an early detection for cancer on the knowledge and attitude of female students of State Vocational High School 1 of Karanganyar. Therefore, the following researchers in the same field are recommended to compare between the health education with lecturing and demonstration methods and the health education with lecturing and video methods two groups, namely: Control Group and Experimental Group.
\end{abstract}

Keywords: Health Education, Knowledge, Attitude, And Breast Self-Examination 


\section{PENDAHULUAN}

Kanker payudara merupakan salah satu jenis kanker yang umum pada wanita. Kanker payudara merupakan tumor ganas yang tumbuh didalam jaringan payudara. Setiap tahun lebih dari 185.000 wanita didiagnosa menderita kanker payudara. Insiden penyakit ini semakin meningkat di negara-negara maju. Sekitar 43.500 kematian akibat kanker payudara setiap tahunnya yang menjadikan penyakit ini sebagai penyebab kematian terbesar kedua setelah kanker paru pada wanita di Amerika Serikat (Kemenkes.RI, 2015).

Menurut WHO (World Health Organization), sekitar $9-8 \%$ wanita berpotensi akan mengalami kanker payudara. Kanker payudara sebagai jenis kanker yang paling banyak ditemui pada wanita. Setiap tahun lebih dari 250.000 kasus baru kanker payudara terdiagnosa di Eropa dan kurang lebih 175.000 di Amerika Serikat (Lumban Gaol \& Briani, 2014).

Data di Indonesia diperkirakan terdapat 100 penderita baru per 100.000 penduduk setiap tahunnya. Ini berarti dari jumlah 237 juta penduduk, ada sekitar 237.000 penderita kanker baru setiap tahunnya. Sejalan dengan itu, data empiris juga menunjukkan bahwa prevalensi kanker meningkat seiring dengan bertambahnya usia. Sekitar 2,2\% kematian semua umur disebabkan oleh kanker ganas. Prevalensi tumor/kanker di Indonesia adalah 1,4 per 1000 penduduk (Kemenkes.RI, 2015).

Berdasarkan data Riset Kesehatan Dasar (2017) prevalensi tumor/ kanker di Indonesia adalah 1.4 per 1000 penduduk, atau sekitar 347.000 orang.Kanker tertinggi di Indonesia pada perempuan adalah kanker payudara dan kanker leher rahim. Berdasarkan estimasi GLOBOCAN (IARC) tahun 2012, insidens kanker payudara masih menempati urutan pertama kasus baru dan kematian akibat kanker, yaitu sebesar 43,3\% dan $12,9 \%$ pada penduduk perempuan di dunia (Kementrian Kesehatan RI Pusat Data dan Informasi Kesehatan, 2015). Berdasarkan data Dinas Kesehatan Provinsi Sulawesi Selatan prevalensi tertinggi untuk penyakit kanker, yaitu sebesar $1,7 \%$. Kanker yang paling banyak diderita oleh masyarakat adalah kanker payudara dan kanker leher rahim (serviks). Data Dinas menyebutkan bahwa penderita kanker seviks dan payudara terbesar di kota Makassar, Kabupaten Gowa, Wajo, Bone, dan Luwu Utara (Kementrian Kesehatan RI Pusat Data dan Informasi Kesehatan, 2015).

Menurut data Buletin Jendela Data dan Informasi Kesehatan, pada penduduk perempuan kanker payudara masih menempati urutan pertama kasus baru dan kematian akibat kanker, yaitu sebesar 43,3\% dan 12,9\% (Badan Penelitian dan Pengembangan Kesehatan, 2013).

Penderita kanker payudara telah banyak ditemukan pada usia muda bahkan tidak sedikit remaja putri usia empat belas tahun menderita tumor dipayudaranya, dimana tumor dapat berpotensi menjadi kanker bila tidak terdeteksi lebih awal (Mboi, 2014).

Satu-satunya cara yang paling efektif yang dapat dilakukan untuk deteksi dini kemungkinan timbulnya penyakit ini adalah dengan melakukan Pemeriksaan Payudara Sendiri (SADARI) yang dapat menekan angka kematian sebesar 25-30\%. Untuk para wanita yang memiliki tingkat pengetahuan dan pemahaman yang rendah tentang kanker payudara dan cara deteksinya perlu diberikan informasi mengenai kanker payudara dan cara deteksinya yaitu SADARI sejak usia remaja (Viviyawati, 2014). Hal ini sejalan dengan penelitian yang dilakukan oleh Savabi-esfahani, Taleghani, Noroozi, \& Tabatabaeian (2017) yang menunjukkan bahwa dari 314 wanita, 113 (36\%) memiliki pengetahuan kurang dan $132 \quad(42 \%)$ memiliki pengetahuan cukup. Lebih dari sepertiga $(38,2 \%)$ mendapatkan informasi tentang kanker payudara dan skrining dari TV dan radio.

Walaupun pemeriksaan SADARI ini merupakan cara yang termudah dan efektif tetapi pada kenyataannya masih banyak wanita khususnya remaja putri yang belum mengetahui tentang kesehatan reproduksinya, khususnya pengetahuan tentang kanker payudara dan praktik SADARI. Hal inidisebabkan karena kurangnya pendidikan kesehatan tentang pemeriksaan SADARI.

Hasil penelitian yang dilakukan oleh Syaiful \& Aristantia (2016) menunjukan bahwa ada perbedaan ketrampilan siswi 
dalam melakukan pemeriksan SADARI.Sehingga hasil penelitian tersebut dapat disimpulkan bahwa pendidikan kesehatan melalui metode demonstrasi tentang ketrampilan praktik SADARI berpengaruh terhadap ketrampilan praktik SADARI di SMA Muhammadiyah 1 Metro. Sedangkan hasil penelitian yang dilakukan di Kabupaten Sukoharjo dengan responden remaja putri berusia 12- 22 tahun didapatkan bahwa sebanyak 133 responden $(65,8 \%)$ memiliki pengetahuan kurang tentang cara melakukan SADARI, 92 responden $(45,5 \%)$ memiliki pengetahuan kurang tentang prosedur SADARI, 95 responden (47\%) memiliki pengetahuan kurang tentang waktu SADARI, dan 94 responden $(46,5 \%)$ memiliki pengetahuan tentang hasil sadari (Handayani \&sudarmiati, 2012).

SMA Swakarya memiliki jumlah populasi siswi kelas X1-a dan Xi-b sebanyak 106 siswi. Sekolah ini dipilih oleh peneliti karena berdasarkan hasil dari data yang diperoleh berdasarkan wawancara yang telah dilakukan pada beberapa guru dan siswi di SMA SWAKARYA diketahui bahwa belum pernah mendapatkan informasi tentang SADARI serta belum pernah diadakan Pendidikan Kesehatan tentang SADARI sebelumnya sehingga menjadi dasar bagi peneliti untuk melakukan penelitian di SMA SWAKARYA.

Berdasarkan uraian di atas peneliti tertarik untuk melakukan penelitian lebih lanjut tentang "Pengaruh Pelaksanaan Pemeriksaan Payudara Sendiri (SADARI) Terhadap Pengetahuan dan Kemampuan Siswi dalam Upaya Deteksi Dini Kanker Payudara di SMA SWAKARYA TAHUN 2017".

Kelenjar yang menempung penyebaran pertama disebut kelennjar penjaga gerbang pengawal. Terkena tidaknya kelenjar ini akan menentukan pilihan terapi. Jika kelenjar ini bebas dari metastatis, penyebaran dikelenjar limfe lain yang letaknya lebih ke atas tidak perlu di fikirkan.

Payudara pada pria dan wanita adalah sama sampai masa pubertas (11-13 tahun) karena hormon estrogen dan hormon lainnya mempengaruhi perkembangan payudara pada wanita. Pada wanita perkembangan payudara aktif, sedangkan pada pria kelenjar dan duktus mammae kurang berkembang dan sinus berkembang tidak sempurna.Payudara yang sensitif terhadap pengaruh hormonal mengakibatkan payudara cenderung mengalami pertumbuhan neoplastik baik yang bersifat jinak maupun ganas.

Payudara merupakan bagian dari organ reproduksi yang fungsi utamanya menyekresi susu untuk nutrisi bayi. Payudara terdiri dari jaringan duktural, fibrosa yang mengikat lobus-lobus, dan jaringan lemak didalam dan diantara lobuslobus.85\% jaringan payudara terdiri dari lemak.Sedikit di bawah pusat payudara dewasa terdapat puting (papila mamaria), tonjolan yang berpigmen dikelilingi oleh areola.

Puting dan areola biasanya mempunyai warna dan tekstur yang berbeda dari kulit di sekelilingnya.Warnanya bermacam-macam dari yang merah muda pucat, sampai hitam dan gelap selama masa kehamilan dan menyusui. Puting susu biasanya menonjol keluar dari permukaan payudara.

Kanker payudara dapat terjadi dibagian mana saja dalam payudara, tetapi mayoritas terjadi pada kuadran atas terluar di mana sebagian besar jaringan payudara terdapat.Dalam menentukan lokasi kanker payudara, payudara dibagi menjadi empat kuadran, yaitu kuadran lateral (pinggir atas), lateral bawah, medial (tengah atas), dan median bawah.

Menurut Nurcahyo (2010) Faktor pemicu atau faktor resiko tumbuhnya sel kanker payudara yaitu:

a. Gender

Ini adalah faktor risiko terbesar gejala kanker payudara. Pria dapat terkena kanker payudara, tapi itu 100 kali lebih sering terjadi pada wanita dibandingkan pria, terutama karena jaringan payudara perempuan jauh lebih terkena hormon seperti estrogen yang mengembangkan pertumbuhan sel abnormal.

b. Umur

Ini adalah salah satu faktor risiko terkuat terserang kanker payudara. Sekitar $85 \%$ kasus terjadi pada wanita usia 50 tahun ke atas, sedangkan 5\% terjadi pada wanita dibawah usia 40 . 
Wanita yang memiliki dua atau lebih kerabat tingkat pertama (ibu, anak perempuan, saudara perempuan) yang pernah mengalami kanker payudara atau ovarium memiliki kemungkinan lebih besar dari $50 \%$ terkena kanker payudara.Salah satu alasan utama untuk risiko ini merupakan mutasi diwariskan dalam salah satu dari dua gen, BRCA1 dan BRCA2. Mutasi gen lain juga dapat mewarisi kanker payudara, tetapi ini jarang dan tidak mempengaruhi resiko kanker payudara.

\section{Gejala kanker payudara sebelumnya}

Jika Anda sudah memiliki kanker pada satu payudara, Anda memiliki risikoempat kali lipat terkena kanker baru pada payudara yang lain atau bagian laindari payudara yang sama. (Ini tidak sama dengan kambuhnya kanker asli).

Wanita dengan jaringan payudara padat, memiliki risiko lebih tinggi terkena kanker payudara dari pada wanita yang payudaranya relatif

Lebih lemak. Proporsi yang lebih besar dari jaringan payudara yang padat pada mammogram, semakin tinggi risikonya.

Wanita yang pernah menjalani biopsi yang menunjukkan suatu pertumbuhan berlebih dari sel-sel (hiperplasia) pada duktus atau lobulus memiliki peningkatan risiko penyakit kanker payudara, terutama jika sel-sel yang abnormal muncul (suatu kondisi yang disebut hiperplasia atipikal).

Wanita yang pernah terkena radiasi tinggi ke dada sebagai bagian dari pengobatan untuk kanker lain (seperti penyakit Hodgkin) memiliki peningkatan risiko terkena kanker payudara, terutama jika mereka menjalani radiasi selama masa remaja.

Semakin lama seorang wanita terkena estrogen, semakin besar risiko terkena kanker payudara. Wanita yang mengalami menstruasi lebih awal, sebelum usia 12, dan atau mengalami menopause terlambat (setelah usia 55) memiliki risiko sedikit lebih tinggi terkena kanker payudara, kemungkinan karena peningkatan paparan seumur hidup terhadap estrogen. Penggunaan kontrasepsi oral saat ini sedikit meningkatkan risiko kanker payudara, tetapi kembali normal setelah pil dihentikan.
Dengan penggunaan terapi hormon postmenopause dengan estrogen plus progestin meningkatkan risiko kanker payudara.

Wanita yang menggunakan DES - obat yang digunakan dari tahun 1940 sampai tahun 1960 untuk mencegah keguguran memiliki risiko sedikit lebih tinggi terkena kanker payudara.

Kelebihan berat badan atau obesitas telah dikaitkan dengan risiko kanker payudara, terutama bagi wanita setelah menopause.Ini mungkin bahwa risiko meningkat pada wanita yang mengalami kenaikan berat badan di masa dewasa tetapi tidak pada mereka yang pernah mengalami kelebihan berat badan sejak kecil.

Wanita yang minum alkohol memiliki peningkatan risiko kanker payudara, dibandingkan dengan wanita yang tidak minum, dan resiko akan meningkat dengan jumlah minuman yang dikonsumsi

Wanita yang telah didiagnosa dengan kanker ovarium, usus besar, endometrium atau lebih mungkin terkena kanker payudara daripada wanita yang tidak memiliki kanker ini.

$\begin{array}{cccr}\text { Risiko } & \text { terjadinya } & \text { kanker } & \text { payudara } \\ \text { meningkat } & \text { pada } & \text { wanita } & \text { yang }\end{array}$ mengalamimenstruasi pertama sebelum umur 12 tahun. Umur menstruasi yang lebih awal berhubungan dengan lamanya paparan hormon estrogen dan progesteron pada wanita yang berpengaruh terhadap proses proliferasi jaringan termasuk jaringan payudara. Penelitian Indriati tahun 2009 di RS Dr. Kariadi Semarang dengan desain case control menunjukkan bahwa diperkirakan risiko bagi wanita yang menarche pada umur $\leq 12$ tahun terkena kanker payudara 3,6 kali lebih tinggi dibandingkan dengan kelompok wanita yang menarche pada umur $>12$ tahun $(\mathrm{OR}=3,6)$.

Menopause setelah usia 55 tahun meningkatkan risiko untuk mengalami kanker payudara. Kurang dari 25\% kanker payudara terjadi pada masa sebelum menapause sehingga diperkirakan awal terjadinya tumor terjadi jauh sebelum terjadinya perubahan klinis.Penelitian Azamris tahun 2006 di RS M. Djamil Padang dengan desain case control menunjukkan bahwa diperkirakan risiko 
wanita yang menopause setelah usia 55 tahun terkena kanker payudara 1,86 kali lebih tinggi dibandingkan dengan kelompok wanita yang menopause sebelum usia 55 tahun $(\mathrm{OR}=1,86)$.

Usia maternal lanjut saat melahirkan anak pertama meningkatkan risiko mengalami kanker payudara. Menurut penelitian Briston (2008) di Amerika Serikat dengan desain cohort, wanita yang kehamilan pertama setelah 35 tahun mempunyai risiko 3,6 kali lebih besar dibandingkan wanita yang kehamilan pertama sebelum 35 tahun untuk terkena kanker payudara $(\mathrm{RR}=3,6)$. Wanita yang nullipara atau belum pernah melahirkan mempunyai risiko 4,0 kali lebih besar dibandingkan wanita yang multipara atau sudah lebih dari sekali melahirkan untuk terkena kanker payudara $(\mathrm{RR}=4,0)$.

berhubungan dengan terjadinya kanker payudara. Wanitayang menggunakan kontrasepsi oral berisiko tinggi untuk mengalami kanker payudara. Kandungan estrogen dan progesteron pada kontrasepsi oral akan memberikan efek proliferasi berlebih pada kelenjar payudara. Wanita yang menggunakan kontrasepsi oral untuk waktu yang lama mempunyai risiko untuk mengalami kanker payudara sebelum menopause.Penelitian Indriati tahun 2009 di RS Dr. Kariadi Semarang dengan desain case control menunjukkan bahwa diperkirakan risiko bagi wanita yang menggunakan kontrasepsi oral > 10 tahun untuk terkena kanker payudara 3,10 kali lebih tinggi dibandingkan wanita yang menggunakan kontrasepsi oral $\leq 10$ tahun $(\mathrm{OR}=3,10)$.

\section{Jenis- jenis Kanker Payudara}

Jenis- jenis kanker payudara menurut Nurcahyo (2010) antara lain:

a. Tumor Jinak (FibroadenomaMamae): Tumor jinak ini berkembang di jaringan dan kelenjar susu.

b. LCIS (Lobular Carcinoma InSitu): LCIS ini tidak meluas tetapi hanya terjebak pada kelenjar susu.

c. DCIS (Ductal Carcinoma InSitu): DCIS adalah perkembangan sel abnormal yang menyerang sel- sel pada saluran susu. d. LC (Infiltrating LobularCarcinoma): Kanker jenis ini menyerang jaringan payudara di bawah kulit, didalam kelenjar susu dan menyebar ke jaringan lemak serta jaringan penyangga payudara.

e. IDC (Infiltrating DuctalCarcinoma): Jenis kanker ini paling banyak menyerang. IDC berawal dari saluran susu dan menyebar melalui aliran sarah serta jaringan limfa ke bagian tubuh lainnya.

\section{Tanda dan Gajala Kanker Payudara}

Umumnya yang menjadi keluhan yaitu adanya benjolan atau massa di payudara, adanya rasa sakit yang dirasakan, keluar cairan dari puting susu, timbulnya kelainan pada kulit (kemerahan, adanya dimpling/ lekukan kedalam), pembesaran kelenjar getah bening.

Menurut Olfah et al. (2013) Tanda dan gejala berdasarkan fase kanker payudara yaitu sebagai berikut:

1. Fase awal

Pada fase awal kanker payudara asimptomatik (tanpa tanda dan gejala).Tanda dan gejala yang paling umum yaitu adanya benjolan dan penebalan payudara.Sekitar 90\% tanda dan gejalanya ditemukan oleh penderita sendiri, dan pada stadium dini kanker payudara tidak menimbulkan keluhan.

\section{Fase lanjut}

Bentuk dan ukuran payudara mulai berubah, berbeda dari sebelumnta. Luka pada payudara tidak kunjung sembuh walaupun sudah diobati. Eksim pada puting susu dan sekitarnya tidak kunjung sembuh. Puting susu terasa sakit, keluar darah, nanah ataupun cairan encer dari puting atau air susu pada wanita yang sedang hamil atau tidak menyusui. Puting susu tertarik masuk kedalam. Kulit payudara mengerut seperti kulit jeruk.

3. Metastase luas

Pembesaran kelenjar getah bening supraklavikula danservikal. Hasil rotgen thorak abnormal dengan atau tanpa efusipleura. Peningkatan alkali fosfatase atau nyeri tulang berkaitan dengan penyebarannya sudah sampai ketulang. .

Pencegahan Kanker Payudara 
Strategi pencegahan yang paling efektif untuk penyakit tidak menularyaitu promosi kesehatan dan deteksi dini, begitupun pada kanker payudara, pencegahan yang dapat dilakukan antara lain sebagaiberikut:

\section{Pencegahan primer}

Pencegahan primer atau pencegahan yang paling utama dilakukan. Caranya adalah dengan upaya menghindarkan diri dari keterpaparan berbagai faktor risiko dan melaksanakan pola hidup sehat (Suryaningsih \& Sukaca, 2009).

2. Pencegahan sekunder

Pencegahan sekunder yang dilakukan terhadap individu yang memiliki risiko untuk terkena kanker payudara adalah dengan melakukan deteksi dini melalui beberapa metode seperti mamografi atau periksa payudara sendiri (SADARI) (Olfah et al., 2013).

3.Pencegahan tersier

Pencegahan tersier yang dilakukan lebih diarahkan kepada individu yang telah positif menderita kanker payudara.Penanganan yang tepat pada kanker payudara disesuaikan dengan stadiumnya agar dapat mengurangi kecacatan dan memperpanjang harapan hidup penderita. Pencegahan tersier bertujuan untuk meningkatkan kualitas hidup penderita serta mencegah komplikasi penyakit dan meneruskan pengobatan. Pencegahan yang dapat dilakukan antara lain:

a. Memberikan ASI selama diyakini dapat menolong untuk mencegah kanker payudara.

b. Diet yang seimbang dan baik serta rendah lemak dan gula, dan sebaiknya dilakukan pada masa kanak-kanak.

c. Sebagian ahli juga percaya bahwa vitamin A (beta carotene) dapat mencegah kanker (Olfah et al.,2013).

\section{Pengertian Pemeriksaan Payudara Sendiri (SADARI)}

Pemeriksaan Payudara Sendiri (SADARI) adalah bagian yang tidak terpisahkan dari pemeriksaan payudara setiap wanita. Pemeriksaan payudara sendiri dilakukan setiap 1 bulan sekali dan dapat menjadi instrumen penapisan yang efektif untuk mengetahui lesi payudara (Varney, 2007).

Sedangkan menurut Smeltzer (2005) SADARI adalah pemeriksaan payudara sendiri antara hari ke -5 dan ke -10 dari siklus menstruasi dengan menghitung hari pertama haid sebagai hari 1 dan menurut Maulani (2009), Pemeriksaan payudara sendiri (SADARI) adalah bagian penting dari perawatan kesehatan, yang dapat melindungi anda dari resiko kanker payudara.

Deteksi dini kanker payudara adalah program pemeriksaan untuk mengenali kanker payudara sewaktu masih berukuran kecil, dan sebelum kanker tersebut mempunyai kesempatan untuk menyebar (Dixon dan Leonard, 2006).Kanker payudara dapat ditemukan secara dini dengan pemeriksaan SADARI, pemeriksaan klinik dan pemeriksaan mamografi. Deteksi dini dapat menekan angka kematian sebesar 25-30\% (Saryono dan Pramitasari, 2009).

\section{Waktu Pemeriksaan SADARI}

a. Usia 20 tahun melakukan SADARI setiap 3 bulan sekali. Wanita usia 20 tahun dianjurkan melakukan SADARI selama 3 bulan sekali agar kanker dapat terdeteksi secara dini. Jika ada benjolan atau hal-hal yang mencurigakan segeralah menghubungi dokter.

b. Usia 35-40 tahun melakukan mamografi.

c. Di atas 40 tahun melakukan check-up pada dokter ahli.

d. Lebih dari 50 tahun check-up rutin dan mamografi setiap tahun.

\section{Pemeriksaan Payudara Mandiri}

Salah satu hal yang penting dalam menjaga kesehatan payudara adalah dengan mewaspadai payudara dari segala kelaianan, terutama yang berkaitan dengan benjolan pada payudara. Umumnya kanker payudara ditemukan pada stadium lanjut akibat kelalaian penderita dalam mendeteksi benjolan ataupun kelainan pada payudaranya. Padahal, kemungkinan sembuh tentu akan semakin besar bila benjolan kanker pada terdeteksi lebih awal.

Pemeriksaan payudara mandiri dapat membantu anda untuk menjadi terbiasa 
dengan tubuh anda, jadi anda dapat menemukan perubahan-perubahan yang terjadi, yakni dengan melihat perubahan di hadapan cermin dan melihat perubahan bentuk payudara dengan cara berbaring.

\section{Cara melakukan SADARI :}

a. Lepas pakaian yang menutupi payudara dan berdirilah di depan cermin dengan tangan rileks disamping badan. Jika Anda tidak dapat berdiri nyaman, boleh juga sambil duduk. Lihatlah dengan seksama payudara Anda apakah ada perubahan atau kelainan sekecil apapun. Beritahu penyedia layanan kesehatan segera jika Anda melihat adanya perubahan atau sesuatu yang aneh.

b. Bandingkan payudara Anda saat berbalik dari sisi ke sisi (kanan-kiri). Carilah setiap perubahan pada payudara dalam segi ukuran, bentuk, tekstur kulit atau warna termasuk kemerahan, benjolan, kerutan atau retraksi (penarikan kulit).

c. Perhatikan perubahan pada puting susu, seperti penarikan ke satu sisi, atau perubahan arah ke samping atau ke dalam.

d. Tempatkan tangan Anda pada pinggang lalu kencangkan dada, kemudian berbalik dari sisi ke sisi bandingkan kanan-kiri untuk mencatat setiap perubahan.

e. Mengencangkan otot dada dengan cara lain juga dapat membantu Anda untuk melihat perubahan. Dengan cara mencoba berbagai posisi, seperti menempatkan tangan di atas kepala dan mengubah dari sisi ke sisi seperti yang Anda lihat.

f. Tempatkan tangan di pinggang dan merunduk didepan cermin, biarkan payudara menggantung. Lalu perhatikan setiap perubahan bentuk.

g. Perhatikan apakah ada cairan yang keluar dari puting susu dan bisa juga dilihat pada bra atau pakaian, tetapi janganlah memencet puting atau mencoba mengeluarkan cairan tersebut. Beritahu penyedia layanan kesehatan jika Anda melihat adanya cairan yang keluar. h. Meraba daerah atas dan bawah tulang selangka (clavicula) apakah ada benjolan atau penebalan. Gunakanlah lotion kulit untuk mempermudah prosedur ini.

i. Periksalah apakah ada benjolan atau penebalan di bawah lengan di sekitar ketiak kearah bawah dan depan (payudara) secara merata kanan dan kiri. Perhatikan setiap perubahan dari permeriksaan (SADARI) sebelumnya.Untuk langkah selanjutnya, dilakukan dengan berbaring.

j. Tempatkan bantal atau lipatan handuk di bawah bahu kiri untuk membantu jaringan payudara merata di dinding dada. Tekuk lengan kiri di belakang kepala dan jangkaulah payudara kiri dengan tangan kanan. Anda dapat menggunakan lotion agar mempermudah prosedur ini.

k. Mulailah pemeriksaan dari ketiak dengan cara menggerakkan tiga jari bersama-sama menekan ringan, sedang dan kuat. Gerakkan jari-jari tangan dengan tekanan ringan secara melingkar searah jarum jam di sekeliling payudara, mulai dari tepi luar payudara lalu bergerak ke arah tengah sampai ke puting susu sehingga terbentuk pola seperti obat nyamuk bakar. Tekan secara perlahan, rasakan setiap benjolan, pengerasan atau massa di bawah kulit.

\section{Pencegahan primer}

Pencegahan primer adalah pencegahan yang paling utama.Caranya adalah dengan upaya menghindarkan diri dari keterpaparan pada berbagai faktor resiko dan melaksanakan pola hidup sehat. Cara ini dilakukan oleh para wanita yang belum sama sekali terdeteksi adanya kanker payudara. Hal ini sangat bagus bila dilakukan, sebab dapat mencegah kanker payudara secara dini.

\section{Pencegahan sekunder}

Terkadang kita tidak tau bahwa kita dapat terkena resiko kanker payudara.Dari pola makan yang salah atau dari riwayat keluarga yang pernah menderita kanker ini.Pencegahan sekunder merupakan pecegahan yang dilakukan terhadap individu 
yang memiliki resiko untuk terkena kanker payudara.

Setiap wanita yang normal dan memiliki siklus haid normal merupakan populasi at risk dari kanker payudara.Pencegahan sekunder dilakukan dengan melakukan deteki dini.Beberapa metode deteksi ini terus mengalami perkembangan.

\section{Pencegahan tersier}

Pencegahan ini ditunjukan pada individu yang telah positif menderita kanker payudara. Penanganan yang tepat sesuai dengan stadiumnya akan dapat mengurangi kecacatan dan memperpanjang harapan hidup penderita. Pencegahan ini untuk meningkatkan kualitas hidup penderita serta mencegah komplikasi penyakit dan meneruskan pengobatan. Tinjuan Umum Tentang Pendidikan Kesehatan.

Pendidikan kesehatan merupakan upayaupaya yang direncanakan untuk mengubah perilaku individu, kelompok, keluarga, dan masyarakat melalui proses pendidikan (Maulana, 2009). Pendidikan kesehatan adalah serangkaian upaya yang dilakukan untuk mempengaruhi orang lain, individu, kelompok, keluarga, maupun masyarakat sehingga terlaksana suatu perilaku hidup bersih dan sehat (Efendi \& Makhfudli,2013).

\section{Tujuan Pendidikan Kesehatan}

Secara umum, tujuan pendidikan kesehatan adalah untuk mengubahgetahuan, sikap, dan keterampilan individu atau kelompok masyarakat dalam bidang kesehatan, dan melihara prilaku hidup sehat.serta berperan aktif dalam upaya mewujudkan derajat kesehatan secara optimal (Nursalam \& Efendi, 2012).

\section{BAHAN DAN METODE}

Lokasi penelitian ini dilakukan di SMA Swakarya Binjai Tahun 2017, dengan alasan berdasarkan survei awal ternyata ada masalah tentang pengetahuan dan kemampuan siswi dalam upaya deteksi dini kanker payudara.Penelitian ini dilaksanakan mulai bulan Juli- Desember 2017.

Populasi adalah seluruh objek penelitian yang diteliti. Populasi pada penelitian ini adalah seluruh siswa kelas XI yang berjumlah 106 orang.

Sampel adalah sekumpulan data yang diambil atau diseleksi dari suatu populasi. Sampel dari penelitian ini adalah siswa kelas XI SMA Swakarya Binjai Tahun 2017. Sampel dalam penelitian ini adalah 106 responden dengan menggunakan metode total sampling yaitu mengambil seluruh total populasi yang akan dijadikan objek yang diteliti.

Penelitian ini bersifat kuantitatif yaitu metode pretest-posttest design dengan cara memberikan pretest (pengamatan awal ) sebelum diberikan intervensi kemudian setelah diberikan intervensi maka diberikan posttest (pengamatan akhir) kembali. Peneliti ingin mengetahui pengaruh pelaksanaan pemeriksaan payudara sendiri (sadari) terhadap pengetahuan dan kemampuan siswi dalam upaya deteksi dini kanker payudara di SMA Swakarya Binjai Tahun 2017.

\section{HASIL}

Tabel 1. Karakteristik usia responden di SMA SWAKARYA

\begin{tabular}{lllc}
\hline No & Variabel kelompok & & Intervensi \\
\hline & Usia & $\mathrm{N}$ & $\%$ \\
1 & 16 & 16 & 52 \\
2 & 17 & 17 & 48 \\
& Total & 31 & 100 \\
\hline
\end{tabular}


Sebagian besar usia responden adalah usia 16 tahun yaitu sebesar $52 \%$.

Tabel 2. Pengetahuan Remaja Putri Sebelum Pendidikan Kesehatan di SMA SWAKARYA

\begin{tabular}{clcc}
\hline No & Tingkat pengetahuan & $\begin{array}{c}\text { Jumlah } \\
(\mathbf{n})\end{array}$ & $\begin{array}{c}\text { Persentase } \\
(\boldsymbol{\%})\end{array}$ \\
\hline 1 & Baik & 0 & 0 \\
2 & Cukup & 26 & 84 \\
3 & Kurang & 5 & 16 \\
& Total & 31 & 100 \\
\hline
\end{tabular}

Pengetahuan remaja putri di SMA SWAKARYA sebelum diberikan pendidikan kesehatan tentang pemeriksaan SADARI sebagian besar dalam kategori cukup yaitu sebesar $84 \%$. Responden yang berpengetahuan cukup sebagian besar kurang mengetahui manfaat dan cara pemeriksaan SADARI. Kurangnya pengetahuan tentang manfaat dan prosedur pemeriksaan SADARI karena kurangnya minat responden untuk mencari informasi tentang kanker payudara dan cara pemeriksaan SADARI baik melalui internet, majalah, brosur ataupun media massa.
Penegtahuan tentang manfaat dan cara pemeriksaan SADARI sangat penting untuk diketahui oleh responden karena manfaatdan cara pemeriksaan SADARI merupakan bagian terpenting dalam SADARI. Pengetahuan yang baik tentang cara pemeriksaan SADARI yang sangat penting dimiliki oleh remaja putrid karena merupakan salah satu alasan untuk mengaplikasikan pemeriksaan SADARI sebagai kegiatan rutin dalam upaya mencegah kanker payudara.

Tabel 3. Pengetahuan Remaja Putri Sesudah Pendidikan Kesehatan di SMA SWAKARYA

\begin{tabular}{clcc}
\hline No & \multirow{2}{*}{ Tingkat pengetahuan } & $\begin{array}{c}\text { Jumlah } \\
(\mathbf{n})\end{array}$ & $\begin{array}{c}\text { Persentase } \\
(\boldsymbol{\%})\end{array}$ \\
\hline 1 & Baik & 31 & 100 \\
2 & Cukup & 0 & 0 \\
3 & Kurang & 0 & 0 \\
& Total & 31 & 100 \\
\hline
\end{tabular}

Pengetahuan remaja putri di SMA SWAKARYA sesudah diberikan pendidikan kesehatan tentang pemeriksaan SADARI semuanya dalam kategori baik. Factor yang mempengaruhi meningkatnya pengetahuan yaitu bertambahnya usia seseorang yang yaitu bertambahnya usia seseorang yang mengalami perubahan aspek fisik dan mental (Mubarak 2012). Usia dapat mempengaruhi tingkat pengetahuan seseorang karena semakin cukup usia, tingkat kematangan dan kekuatan seseorang akan lebih matang dalam berfikir dan bekerja (Wawan \& Dewi 2011). Usia 1617 tahun merupakan usia reproduksi dimana saat ini termasuk periode usia subur (menstruasi) seorang wanita, dan hal tersebut dapat memicu terjadinya kanker payudara (Nurcahaya 2010).

Tabel 4. Sikap Remaja Putri Tentang Pemeriksaan SADARI Sebelum Pendidikan Kesehatan di SMA SWAKARYA

\begin{tabular}{clll}
\hline No & Sikap & Jumlah (n) & Persentase (\%) \\
\hline 1 & Positive & 4 & 13 \\
2 & Negative & 27 & 87 \\
Total & & 31 & 100 \\
\hline
\end{tabular}


Tabel 5. Sikap Remaja Putri Tentang Pemeriksaan SADARI Sesudah Pendidikan Kesehatan di SMA SWAKARYA

\begin{tabular}{clccc}
\hline No & & Sikap & Jumlah & Persentase \\
\hline 1 & Positif & 24 & 77 \\
2 & Negatif & 7 & 23 \\
& total & 31 & 100 \\
\hline
\end{tabular}

Sikap remaja putri di SMK N 1 Karanganya sesudah diberikan pendidikan kesehatan tentang pemeriksaan SADARI seba gian besar dalam kategori positif yaitu sebesar 77\%. Pengalaman pribadi merupakan salah satu faktor yang mempengaruhi sikap seseorang. Teori menyebutkan bahwa untuk dapat menjadi dasar pembentukan sikap, pengalaman pribadi haruslah meninggalkan kesan yang kuat. Media massa juga berpengaruh terhadap sikap seseorang karena berita yang seharusnya factual disampaikan secara obyektif cenderung dipengaruhi oleh sikap penulisnya, akibatnya akan berpengaruh terhadap sikap konsumennya (Wawan \& Dewi 2011). Selain faktor pengalaman pribadi dan media massa, ada tahap motivasi yang merubah seseorang setelah mengikuti pendidikan kesehatan benar-benar mengubah perilaku sehari-hari (Azwar dikutip dalam Susilo 2011).

\section{Tabel 6. Pengetahuan Pre Test Dan Post Test Remaja Putri Tentang Pemeriksaan SADARI di} SMA SWAKARYA

Pengetahuan setelah pendidikan sekolah

\begin{tabular}{llllll}
\hline & & B & C & K & P \\
& & & & & \\
\hline Pengetahuan & B & 0 & 0 & 0 & 0 \\
$\begin{array}{l}\text { Sebelum } \\
\text { Pendidikan }\end{array}$ & C & 26 & 0 & 0 & 26 \\
Kesehatan & & 5 & 0 & 0 & 5 \\
\hline Total & & 31 & 0 & 0 & 31 \\
\hline
\end{tabular}

Ranks Test diperoleh nilai $\mathbf{P}=0.000$ karena nilai $\mathrm{P}<0,05$ maka $\mathrm{H} 1$ diterima yaitu ada pengaruh pendidikan kesehatan tentang pemeriksaan SADARI sebagai deteksi dini kanker payudara terhadap pengetahuan remaja putri di SMA SWAKARYA pendidikan kesehatan tentang pemeriksaan SADARI sangat mempengaruhi terhadap pengetahuan remaja putrid. Pendidikan kesehatan merupakan suatu kegiatan yang dapat meningkatkan pengetahuan (Adnani 2011).

Pengetahuan merupakan hasil dari tahu dan ini terjadi setelah orang mengadakan penginderaan terhadap suatu objek tertentu. Pengetahuan sangat dipengaruhi oleh intensitas perhatian persepsi terhadap objek (Wawan \& Dewi 2011). Remaja putri di SMA SWAKARYA saat pendidikan kesehatan berlangsung, remaja putrid memperhatiakan dengan seksama sehingga dapat menambah pengetahuan tentang pemeriksaan SADARI. Alas an terjadinya peningkatan skor pengetahuan pada remaja putrid untuk memperhatikan pendiidkan kesehatan tentang SADARI menggunakan metode ceramah dan demonstrasi.

\section{PEMBAHASAN}

Pengaruh Pelaksanaan Pemeriksaan Payudara Sendiri (Sadari) Terhadap Pengetahuan Dan Kemampuan Siswi Dalam Upaya Deteksi Dini Kanker Payudara

Tingkat pengetahuan tentang SADARI pada siswi SMA SWAKARYA sudah baik. Dibuktikan dari hasil penelitian, diperoleh distribusi tingkat pengetahuan tinggi sebanyak $57 \%$, tingkat pengetahuan sedang sebanyak $40,8 \%$ dan tingkat pengetahuan rendah sebanyak 2,2\%. Perilaku SADARI pada siswi SMA SWAKARYA sudah cukup baik. Dibuktikan dari hasil penelitian, diperoleh distribusi perilaku baik sebanyak 47,3\%, perilaku cukup baik sebanyak $44,1 \%$ dan perilaku kurang baik sebanyak $8,6 \%$. 
Terdapat hubungan positif dan signifikan antara tingkat pengetahuan tentang SADARI dengan perilaku SADARI pada siswi SMA SWAKARYA dengan tingkat korelasi sedang.

\section{KESIMPULAN}

Tingkat pengetahuan remaja putri sebelum pendidikan SADARI di SMA SWAKARYA sebagian besar dalam kategori cukup dan sikap remaja putri sebelum pendidikan kesehatan tentang pemeriksaan SADARI di SMA SWAKARYA sebagian besar dalam kategori cukup dan sikap remaja putrid sebelum pendidikan kesehatan tentang pemeriksaan SADARI di SMA SWAKARYA sebagaian besar dalam kategori negaif. Tingkat pengetahuan remaja putri sesudah pendidikan kesehatan tentang pemeriksaan SADARI di SMA SWAKARYA semuanya dalam kategori baik, dan sikap remaja putrid sesudah pendidikan kesehatan tentang pemeriksaan SADARI di SMA SWAKARYA sebagian besar dalam kategori positif. Ada pengaruh pendidikan kesehatan tentang pemeriksaan SADARI terhadap pengetahuan remaja putri di SMA SWAKARYA. Ada pengaruh pendidikan kesehatan tentang pemeriksaan SADARI terhadap sikap remaja putrid di SMA SWAKARYA.

\section{SARAN}

Sebaiknya peneliti lain dapat melakukan penelitian lanjutan dengan cara membandingkan pendidikan kesehatan dengan penggunaan metode ceramah dan metode demontrasi dengan metode ceramah dan metode video, dan dengan dua kelompok yaitu kelompok kontrol dan kelompok intervensi. Jumlah responden minimal 50 responden dan tidak ada batasan waktu dalam penelitian. Sebaiknya bagi para bidan saat melakukan pendidikan kesehatan tentang pemeriksaan SADARI menggunkan metode ceramah dam demonstrasi agar lebih mudah untuk dimengerti.

\section{DAFTAR PUSTAKA}

Apriani. 2014. Analisis Faktor yang Berhubungan dengan Respon Psikologis Mahasiswa Fisioterapi Fakultas Kedokteran Universitas Hasanuddin. Skripsi. Tidak dipublikasikan. Makassar: Universitas Hasanuddin

Asmarani, Rima. 2010. Pengaruh Olahraga Terhadap Siklus Haid Atlit. Skripsi.
Tidak dipublikasikan. Semarang: Universitas Diponegoro

Atkinson, Smith, dkk. (2000). Introduction to Psychology (13thEdition). Harcourt College Publisher.

Bobak, Irene M. 2009. Buku Ajar Keperawatan Maternitas. Edisi 5. Jakarta: EGC

Carolin. 2011. Gambaran Tingkat Stres Pada Mahasiswa Pendidikan Sarjana Kedokteran. Skripsi. Tidak dipublikasikan. Medan: Universitas Sumatera Utara.

Dorland, W. A. Newman. 2012. Kamus Kedokteran Dorland. Edisi 28. Jakarta: Buku Kedokteran EGC.

Fitria, A. 2007. Panduan Lengkap Kesehatan Wanita. Yokyakarta: Gala Ilmu Semesta.

Govarest, S. and Gregoire, J. 2004. Stressfullacademic Situations: Study on Appraisil Variables in Adolescence. British journal of Clinical Psychology, 54, 261-271.

Habeeb, Kholoud Abdulrahman. 2010. Prevalence of Stressors Among Female Medical Student. Journal of Taibah University Medical Sciences. 5(2): 110-119

Hamidi. 2007. Metode Penelitian Dan Teori Komunikasi (Pendekatan Praktis Penulisan Proposal Dan Laporan Penelitian). Malang: Penerbitan Universitas Muhammadiyah Malang.

Harahap, Juliana Sari. 2013. Hubungan Indeks Massa Tubuh dengan Siklus Menstruasi Pada Mahasiswi Fakultas Kedokteran Universitas Sumatera Utara. Skripsi. Tidak dipublikasikan. Medan: Universitas Sumatera Utara.

Hawari, D. 2008. Manajemen Stres Cemas dan Depresi. Edisi Kedua, Cetakan kedua. Jakarta: Balai Penerbit FKUI.

Isnaeni, Desty Nur. 2010. Hubungan Antara Stres Dengan Pola Menstruasi Pada Mahasiswa D IV Kebidanan Jalur Reguler. Skripsi. Tidak Dipublikasikan. Surakarta: Universitas Sebelas Maret. 52

Kamus Gizi Pelengkap Kesehatan Keluarga. 2009. Persatuan Ahli Gizi Indonesia (Persagi).

Kholifah, Ai. 2013. Gambaran Tingkat Stres Pada Anak Usia Sekolah Menghadapi Menstruasi Pertama (Menarche) Di Sekolah Dasar Negeri Gegerkalong Girang 2. Skripsi. Tidak Dipublikasikan. Girang: Universitas Pendidikan Indonesia. 
Koochaki, G.M., et al. 2009. Prevalence of Stress Among Iranian Students. Eastern Mediterranean Health Journal. 17(7): 593594

Kriyantono, Rachmat. 2008. Teknik Riset Komunikasi: Disertai Contoh Praktis Riset Media, Public Relations, Advertising, Komunikasi Pemasaran. Jakarta: Kencana Prenada Media Group.

Kusmiran, E. 2011. Kesehatan Reproduksi Remaja Dan Wanita. Jakarta: Salemba Medika.

Lavibond, S. H. \& Lavibond, P. F. 1995. Manual for Depression Anxiety and Stress Scale. 2thed. Sydney: Psychology Foundation.
Mansjoer, A. 1999. Kapita Selekta Kedokteran. Edisi ketiga. Jilid 1. Jakarta: Fakultas Kedokteran Universita Indonesia.

Mulastin. 2013. Hubungan Stres dengan Siklus Menstruasi pada Wanita Pekerja di Desa Pelemkerep Kecamatan Mayong Kabupaten Jepara. Artikel Penelitian. Tidak dipublikasikan. Jepara.

Nasution, Indri Kemala. 2007. Stres Pada Remaja. Penelitian. Tidak Dipublikasikan. Medan: Univesitas Sumatera Utara.

Nurlaila, dkk. 2015. Hubungan Stres Dengan Siklus Menstruasi Pada Mahasiswa Usia 18-21 Tahun. Jurnal Husada Mahakam. Vol 3: hal 452-521. 